\title{
ASSESSMENT OF THE IMPACT OF PESTICIDES ON THE SOIL MICROBIAL COMMUNITY USING INTACT POLAR MEMBRANE LIPIDS AS BIOMARKERS
}

\author{
M. Suleman ${ }^{1,2, *}$, B. J. Keely ${ }^{1}$, S. Liaqat ${ }^{3}$ and W. $\mathrm{Ali}^{4}$ \\ ${ }^{1}$ Department of Chemistry, University of York, York, United Kingdom, YO10 5DD, \\ ${ }^{2}$ Department of Agricultural Chemistry, The University of Agriculture, Peshawar, Pakistan, 25130, \\ ${ }^{3}$ Department of Chemistry, Lahore College for Women University, Lahore Pakistan \\ ${ }^{4}$ Department of Biotechnology, The University of Malakand \\ Corresponding Author: Muhammad Suleman; Email; suleman@aup.edu.pk
}

https://doi.org/10.36899/JAPS.2020.1.0022

Published online January 02, 2020

\begin{abstract}
Intact polar membrane lipids (IPLs) have recently been used as biomarkers to assess the diversity in microbial community as a result of stress conditions. Present study was aimed to investigate the impact of pesticides and their transformation products (TPs) on the soil microbial community. Soil was treated with isoproturon (IPU), glyphosate (GLYP), thifesulfuron methyl, propyzamide and their TPs at their maximum application rates. After seven weeks, IPLs were extracted from the soil and analysed by HPLC ESI-MS ${ }^{\mathrm{n}}$. The method was sensitive and effectively separated different classes of polar lipids on the basis of their head groups. The IPL profiles of IPU, GLYP and PROP treated soil showed significant $(\mathrm{p}<0.05)$ variations among the abundance of the polar lipids due to pesticide application. The impact of the pesticides was more obvious in changes induced in the relative amounts of phosphatidyl choline (PC), diacylglycerol trimethylhomoserine (DGTS), phosphatidyl ethanolamine (PE), monomethyl phosphotidyl ethanolamine (PMME), monogalactosyl diacylglycerol (GL) and phosphatidyl glycerol (PG). It was concluded that the botanical pesticides and their TPs can induce changes in soil microbial diversity. Moreover, IPLs can be used as biomarkers for the assessment of the microbial response toward environmental stressors.
\end{abstract}

Key words: Intact polar membrane lipids (IPLs), soil microbial diversity, liquid chromatography-tandem mass spectrometry (LC-MS/MS), pesticides, transformation products, phospholipids, betaine lipids

\section{INTRODUCTION}

Pesticides are used repeatedly, usually in large volumes, neglecting their impact on soil microbial communities. The impact of pesticides and their transformation products on soil health is an emerging issue. Long term agricultural sustainability and productivity depends on maintaining favourable chemical, biological and physical features of the soil (Arias et al., 2005). Soil is heterogeneous mixture of organic and inorganic substances where chemical, biological and physical changes occur at the molecular level. Hence, as light disturbance in composition can result in a significant change in suitability for agricultural use. Microorganisms, being important players within the ecosystem, take part in the global nitrogen cycle, decomposition of organic matter and release of nutrients, hence are crucial in promoting plant health (Pankhurst et al., 1995).

The impacts of pesticides on the distribution, structure and function of soil microbial communities have been investigated previously (Bending et al., 2007; Seghers et al., 2003; Martins et al., 2003). Due to the limited knowledge of the soil microbial diversity, and difficulties and limitations of some methods for their assessment, it is important to select a method for the assessment that reveals changes in microbial community structure in response to pesticide applications. Various different molecular and biochemical techniques have been used to study soil microbial communities. As only $1 \%$ of soil bacterial and fungal populations can be cultured by standard laboratory methods (Torsvik et al., 1998; Van Elsas et al., 2000), suitable; culture independent techniques are the methods of choice.

Analysis of whole cellular fatty acid distributions as methylesters (FAMEs) (Graham et al., 1995; Zelles 1999) and phospholipid ester-linked fatty acids (PLFAs) are biochemical methods that have been shown to be suitable for studying the changes in microbial communities and their physiological processes in soil ( Peacock et al., 2001; Baldrian et al., 2013). These techniques provide useful information about fatty acid compositions, some of which can be used as exclusive markers for certain microorganisms. Distributions of FAMEs and PLFAs, however does not provide important information about the polar head groups and the respective fatty acids within individual lipid molecules. Analysis of intact polar membrane lipids 
(IPLs) can be a powerful tool to investigate viability and diversity in microbial populations and can be used to trace changes in the microbial communities in complex matrices such as soil, sediments and oceans (; Zink et al., 2003; Sturt et al., 2004; Laura et al., 2010; Willers et al., 2015). The comparison of various methods to study the microbial diversity has been clearly elaborated in the literature elsewhere (Willers et al., 2015). The ESI-LC $\mathrm{MS}^{\mathrm{n}}$ analysis of IPLs provide information about the head groups, molecular species of each class of lipids, position and composition of their fatty acids side chains inventories (Zink and Mangelsdorf 2004; Zink et al., 2008).

The present study was focused on assessment of the impact of selected pesticides and their TPs, as potential stressors, on the IPLs of the soil microbial community. During the present study LCESI-MS method was also developed and employed for the separation and identification of the IPLs distribution in soil. A semiquantitative approach was used to quantify the relative abundances of microbial IPLs of the experimental soil.

\section{MATERIALS AND METHODS}

Acetonitrile, 2-propanol, water, dichloromethane, chloroform, acetic acid and methanol were of HPLC grade (Fischer Scientific UK, Loughborough, UK), Standards (purity $>99.0 \%$ ) of isoproturon (IPU), glyphosate (GLYP), thifensulfuron methyl (TSM), aminomethyl phosphonic acid (AMPA), and propyzamide (PROP) were purchased from $\mathrm{Q}_{\mathrm{mx}}$ laboratories (Thaxted, UK). For IPLs analysis, sheep brain mixed phospholipids standard (Sigma-Aldrich, UK) was used as reference standard to optimise LCMS/MS conditions.

Soil Samples: A sandy clay loam soil was collected from an uncultivated field in Heslington East, York, UK, air dried and sieved through a $2 \mathrm{~mm}$ screen and filled in PVC pipes $(30 \mathrm{~cm}$ long with $6.4 \mathrm{~cm}$ diameter) to prepare soil columns for pesticides leaching studies (Suleman and Keely, 2019). pesticides standards; IPU and MDIPU were applied at $1.25 \mathrm{~kg} \mathrm{ha}^{-1}$, GLYP and AMPA at $1.080 \mathrm{~kg} \mathrm{ha}^{-}$ , , TSM at $120 \mathrm{~g} \mathrm{ha}^{-1}(2 \times$ maximum recommended rate/ha due to a very low recommended field application rate) and PROP at $2.40 \mathrm{~kg} \mathrm{ha}^{-1}$. An equal volume of artificial rain was applied to each core at specific intervals. At the end of the leaching experiments, soil cores were sliced and a section of approximately $25 \mathrm{~cm}$ long and $2-2.5 \mathrm{~cm}^{2}$ was taken from the centre of each intact soil core. Homogenous mixtures of the selected portions of the soil cores were used for lipid analysis.

Polar lipid extraction: A LLE method developed by Bligh and Dyer (1959) and modified by Sturt et al. (2004) was used for the extraction of the soil microbial IPLs. A soil sample of $20 \mathrm{~g}$ from each soil core was collected. Methanol (MeOH): dichloromethane (DCM): $50 \mathrm{mM}$ phosphate buffer $\mathrm{pH} 7.5(2: 1: 0.8 \mathrm{v} / \mathrm{v})$ was added to the sample and transferred to a falcon tube rinsed with phosphate buffer $(50 \mathrm{mM})$. The soil sample was well mixed in the solvent and sonicated in a water bath for 10 min prior to centrifugation for $5 \mathrm{~min}$ (2500rpm). The organic layer was collected in a round bottom flask. The extraction process was repeated twice and extracts were pooled. For phase separation, DCM and phosphate buffer were added to achieve final proportion of 1:1: $0.8(\mathrm{v} / \mathrm{v})$ for $\mathrm{MeOH}, \mathrm{DCM}$ and phosphate buffer, respectively. The organic layer was collected in a round bottom flask. The total lipid extract was dried using a vacuum centrifuge (Christ) at $15{ }^{\circ} \mathrm{C}$ and stored in a refrigerator. Total lipid extract was dissolved in a minimal volume of DCM and loaded onto activated silica column $(5 \mathrm{~mm}$ x $50 \mathrm{~mm})$ prewashed with DCM. Non-polar lipids fractions were removed via flushing with three bed volumes of DCM. Three bed volumes of acetone were used to remove the glycolipids while same volume of $\mathrm{MeOH}$ was used to collect the polar lipids fraction, containing phospholipids and betaine lipids. The $\mathrm{MeOH}$ fraction was dried under gentle flow of nitrogen prior to ESI-LCMS analysis.

Liquid chromatography-tandem mass spectrometry: Liquid chromatography-tandem mass spectrometry was used for IPLs analysis. Chromatographic separation was achieved on a silica column $(250 \mathrm{~mm} \times 4.6 \mathrm{~mm}$ x $5 \mu \mathrm{m}$; Phase Sep) with mobile phases: chloroform (A), methanol (B), ammonium acetate (C) $(0.01 \mathrm{M}, \mathrm{pH} 7.5)$ and acetonitrile (D). The column was held at $25^{\circ} \mathrm{C}$ and IPLs were eluted by a gradient program at $0.8 \mathrm{mLmin}^{-1}$ with quaternary solvent that started from $80 \% \mathrm{~A}, 14 \% \mathrm{~B}$ and $1 \% \mathrm{C}$ while $\mathrm{D}$ remained constant at $5 \%$ during the entire run. Lipids were detected online through the use of an HCT ultra ECD-II ion trap mass spectrometer (Bruker Daltonics, Coventry, UK) equipped with an electrospray ionisation source, operated in positive ion mode over the range $\mathrm{m} / \mathrm{z} 500-2000$ and set to select the base peak ion in each scan for CID (isolation width $=2 \mathrm{~m} / \mathrm{z}$ units; fragmentation amplitude $=0.65 \mathrm{~V}$ along with smart fragmentation with a range of 100-150 \%), drying temperature was set to $250{ }^{\circ} \mathrm{C}$, drying gas $8.0 \mathrm{~L} / \mathrm{min}$ and nebuliser gas 40.0 psi was used. Individual ion chromatograms were generated by selecting all ions within $\pm 0.5 \mathrm{~m} / \mathrm{z}$ units of the target $\mathrm{m} / \mathrm{z}$ value. Tandem mass spectra are reported as the average spectra obtained over the full width of the relevant chromatographic peak. The relative concentration of the IPLs was determined on the basis of signal response over the peak area of the individual polar lipids class and normalised to 100 .

Statistical analysis: The data set was analysed to find out the means IPLs values with standard error using SPSS 19.0 (IBM Corp. 2010). One-way ANOVA was used for each of the pesticide-treated soil and control soil. LSD test was performed to identify the differences 
(significance level $\mathrm{p}<0.05$ ) between pesticide treated and

\section{RESULTS}

LCMS $^{\text {n }}$ method development for the analysis of IPLs: Total IPL extracts of the control and pesticide-treated soils were analysed by +ESI LCMSn. The base peak chromatogram for the Heslington East soil shows a range of different IPL classes with wide range of fatty acid side chains (Fig. 1). The membrane lipids diacylphosphatidyl cholines (PC) were dominant in the soil. The other lipids were diacylphosphatidyl ethanolamine (PE), diacylphosphatidylmono-methyl ethanolamine (PMME), diacylphosphatidyl dimethyl ethanolamine (PDME), glycolipids (GL), diacylphosphatidylglycerol (PG) and a betaine lipid diacylglycerol-N,N,N-trimethyl homoserine (DGTS). Several unknown compounds were also observed during the analysis. The compound $U$ is also unknown but being in a high abundance, was considered in the studies. All of the polar lipids were identified and confirmed by their retention times and CID patterns in MS/MS and MS.3

Glycerophosphatidyl choline (PC): The positive charge on the quaternary nitrogen atom is neutralised by the negative charge of the phosphate group present, hence a protonated molecular species $\left([\mathrm{M}+\mathrm{H}]^{+}\right.$is readily formed during +ESI analysis of PC. Generally, product ion spectra of the $[\mathrm{M}+\mathrm{H}]^{+}$ions of $\mathrm{PC}$ are dominated by a phospho choline ion at $\mathrm{m} / \mathrm{z} 184$ and contain very low intensity ions relating to the other structural features (Pulfer and Murphy, 2003; Hsu and John, 2009). The MS/MS of PC observed during the present study showed a neutral loss of phospho choline $(-183 \mathrm{Da})$. Other product ions formed as a result of CID of PC can be used for the structural elucidation of $\mathrm{PC}$. The $\mathrm{MS}^{3}$ spectrum from $\left[\mathrm{M}+\mathrm{H}-\mathrm{R} 2 \mathrm{C} \mathrm{H}=\mathrm{C} \mathrm{O}^{+}\right.$contain an ion at $\mathrm{m} / \mathrm{z} 184$ corresponding to a phospho choline head group, corroborating the identification as a PC.

The MS/MS dissociation of $\mathrm{m} / \mathrm{z} 760.6$ (1palmitoyl-2-oleoyl-phosphotidyl choline (16:0/18:1)) shows a neutral loss of phospho choline, giving a product ion at $\mathrm{m} / \mathrm{z} 577[\mathrm{M}+\mathrm{H}-183]^{+}$. An intense product ion at $\mathrm{m} / \mathrm{z} 701$ observed during MS/MS of $[\mathrm{M}+\mathrm{H}]^{+}$arises from neutral loss of $59 \mathrm{Da}$, corresponding to a trimethylamine moiety $(\mathrm{N}(\mathrm{CH} 3) 3$ ) from the phospho choline head group. (Fig. 2 \& Fig. 3)

Diacylglyceroltrimethyl homoserine (DGTS): During IPL analysis of control and pesticide-treated soils, a group of compounds eluted at a retention time $9.6 \mathrm{~min}$ with predominantly protonated ions comprising several molecular species of that compound class. The tandem $\mathrm{MS}$ of $\mathrm{m} / \mathrm{z} 738$ (the most intense ion) produces an ion at $\mathrm{m} / \mathrm{z} 500$ consistent with the neutral loss of a C16:0 fatty acyl chain in the form of a ketene of $238 \mathrm{Da}$ $([\mathrm{C} 14 \mathrm{H} 29 \mathrm{CH}=\mathrm{C}=\mathrm{O}])$. A product ion at $\mathrm{m} / \mathrm{z} 236$ was also observed during MS/MS. Subsequent loss of a water control soil. All the samples were in triplicates.

molecule (18 Da) from m/z 500 yields an ion at m/z 482 . Similarly, the ion at $\mathrm{m} / \mathrm{z} 476$ most likely forms by a neutral loss of C18:1 fatty acyl chain (-264Da) from the precursor ion and subsequent loss of water gives the ion at $456 \mathrm{~m} / \mathrm{z}$. Product ions with $\mathrm{m} / \mathrm{z}$ values of 144 and 162 were formed during $\mathrm{MS}^{3}$ (Fig.4).. The product ions at $\mathrm{m} / \mathrm{z}$ 236 (represent the head group with a glycerol moiety), $\mathrm{m} / \mathrm{z} 162$ (represent the polar head group) and $\mathrm{m} / \mathrm{z} 144$ (dehydrated product of the head group) (Fig. 5) can be used as diagnostic ions for the detection and identification of DGTS (Evans et al., 1982; López-Lara et al., 2005).

Ether linked glycerolipids containing DGTS have a quaternary ammonium groups that resemble PCs, and can be detected in + ESI mode as $[\mathrm{M}+\mathrm{H}]^{+}$. In these lipids the betaine head group is linked through an ether bond to the sn-3 position of the glycerol backbone. The fatty acids are ester-linked to positions sn-1 and sn-2 of glycerol moiety.

Glycerophosphatidyl ethanolamine (PE) and its derivatives: The identification of $\mathrm{PE}$ was carried out on the basis of its retention time $(10.5 \mathrm{~min})$ and its CID pattern in MS/MS and $\mathrm{MS}^{3}$. The MS/MS of the $[\mathrm{M}+\mathrm{H}]^{+}$ at $\mathrm{m} / \mathrm{z} 744.6$ shows an intense product ion at $\mathrm{m} / \mathrm{z} 603.5$ $([\mathrm{M}+\mathrm{H}-141]+)$ during $\mathrm{MS} / \mathrm{MS}$, while $\mathrm{MS} 3$ of the production $\mathrm{m} / \mathrm{z} 603.5$ produces ions at $\mathrm{m} / \mathrm{z} 529.5$ (-74 Da; glycerol loss), m/z 339 (-264Da; fatty acyl in the form of a ketene loss), m/z 321 (-282 Da; fatty acid loss), m/z 265 corresponding to fatty acyl (18:1) and a subsequent loss of water to give $\mathrm{m} / \mathrm{z} 247$. PE generally shows a neutral loss of 141 that corresponds to its head group (Pulfer and Murphy 2003; Sturt et al., 2004). The base peak chromatogram shows that PMME and PDME elute after PE. The MS/MS spectra of both PMME and PDME reveal that both undergo the same dissociation pathways as PE, losing the head groups as neutral losses of 155 and $169 \mathrm{Da}$, respectively.

Monoglycosyldiacyl glycerol (MGDG): The LC-MS of the IPLs show that glycolipids elute earlier than the other lipids. Their retention times, ammoniated species $[\mathrm{M}+\mathrm{NH} 4]^{+}$and their MS/MS confirmed the presence of mono hexose in their structure. Generally, glycolipids ionised well in negative ESI mode, however, in the presence of excess of $\mathrm{NH}^{+}$they can also be analysed in positive ESI mode as well. The diagnostic 162 Da neutral loss during MS/MS of the protonated molecule confirmed the loss of hexose sugar from the parent molecule.

Glycerophosphatidyl glycerol (PG): A group of the compounds co-eluted with DGTS had ammoniated molecular species. A neutral loss of 189 Da (corresponding to ammoniated phosphoglycerol head group) was noticed during MS/MS of the parent ammoniated molecule. So on the basis of their retention 
time (9.4 min) and CID pattern during MS/MS, the compound class was assigned as diacylphosphatidyl glycerol (PG). Being acidic in nature $P G$ is efficiently ionised in negative mode ESI, however, in the presence of excess of $\mathrm{NH}_{4}^{+} \mathrm{PG}$ can analyse in positive mode ESI as well.

\section{Impact of pesticides on the relative abundances of the soil IPLs}

IPLs of Control and pesticides treated soils: IPLs of control soil was predominantly by PC (56.27\%) followed by DGTS (15.84\%). Similarly, PE, MMPE and DMPE were also present at $6.97 \%, 2.39 \%$ and $2.95 \%$. While other polar lipids such as GL (1.52\%) and PG $(2.35 \%)$ were also present relatively low amount. There was an unknown compound (U) that was present at $11.69 \%$. IPLs of IPU treated soil also contain the same classes of polar lipids (Fig. 6). IPLs of IPU-treated soil showed significantly lower amount of PC (50.61\%), PE (4.88\%) and PG $(0.56 \%)$. The amount of DGTS was however significantly increased as compared to untreated control soil. Mono and dimethyl species of PE were present but not significantly different from the control (Fig. 6). The main TP of IPU, MDIPU-treated soil showed significantly higher amount of DGTS (23.71\%). The amount of PC $(51.42 \%)$ and PG $(0.72 \%)$ were however significantly decreased as result of MDIPU treatment (Fig. 7). Contrary to its parent compound IPU, MDIPU application did not affect the amount of PE $(6.76 \%)$ and related MMPE (1.72\%), and DMPE (2.47\%).
GLYP-treatment soil contained GL (0.47\%) and PG $(0.44 \%)$ significantly lower than that of the control, however, DGTS $(24.24 \%)$ was increased significantly as a result of GLYP treatment (Fig. 8). The amount of PC (50.8\%), PE (5.88\%) and its mono and dimethyl species i.e., MMPE (1.72\%) and DMPE (3.13\%) remained unaffected. Likewise, its parent pesticide GLYP, the AMPA-treated soil also showed a significant changes in certain classes of IPLs (Fig. 9), specifically decreased in the amount of PC (51.78\%) and PG (0.78\%). Similarly, the impact of AMPA on the diversity of soil microbial community was seen more obvious in changes in DGTS level $(22.91 \%)$.

IPLs profile of PROP-treated soil also resulted in a significant increased in the DGTS amount $(25.36 \%)$ as result of PROP application (Fig. 10). The amount of PC (48.68\%) showed a similar trend just like the other pesticide treated soil and decreased significantly as compared to control. Some minor changes in the relative amounts of other important polar lipids such as GL, PE, MMPE and DMPE were reported.

TSM-treated soil showed no significant changes in the microbial IPLs (Fig. 11). The IPLs profile was similar to that of the control. Some subtle changes were reported in $\mathrm{PC}$ and $\mathrm{U}$ as compared to the other pesticide treated soil. The highest PC amount (58.45\%) was reported than the control while the lowest amount of $U$ $(9.92 \%)$ was found in TSM-treated soil than all the other soil samples including control and pesticide treated soils.

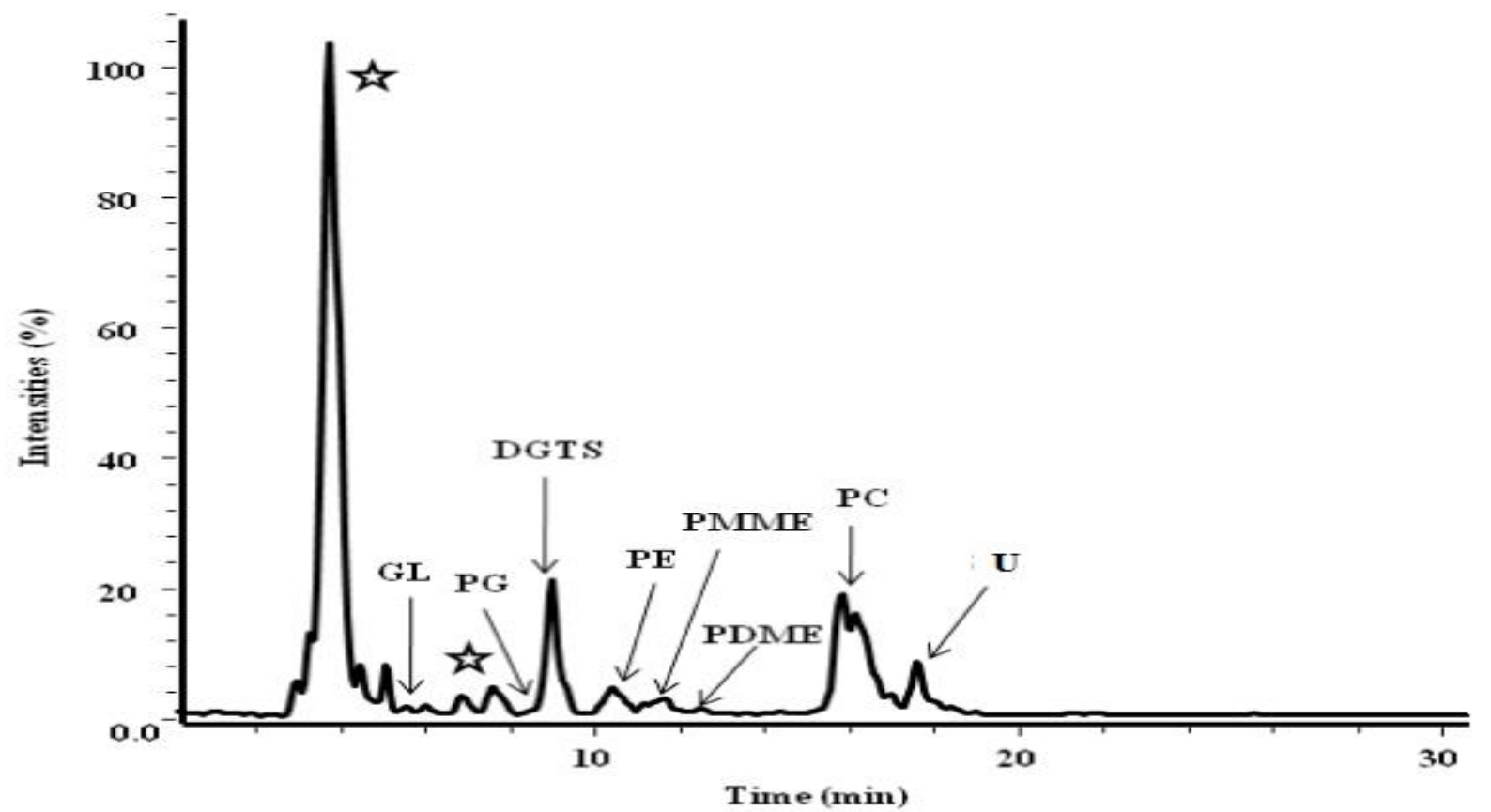

Fig. 1. +ESI LCMS base peak chromatogram of polar lipids extract of Hesligton East soil sample. The chromatogram reveals the distribution of polar lipids including GL,PG,DGTS,PE,PMME,PDME,PC,U 
(a group of similar unknown compounds) and unknown compounds denoted by *. The structures of the polar lipids were confirmed by their MS/MS and $\mathrm{MS}^{3}$ dissociation pattern.

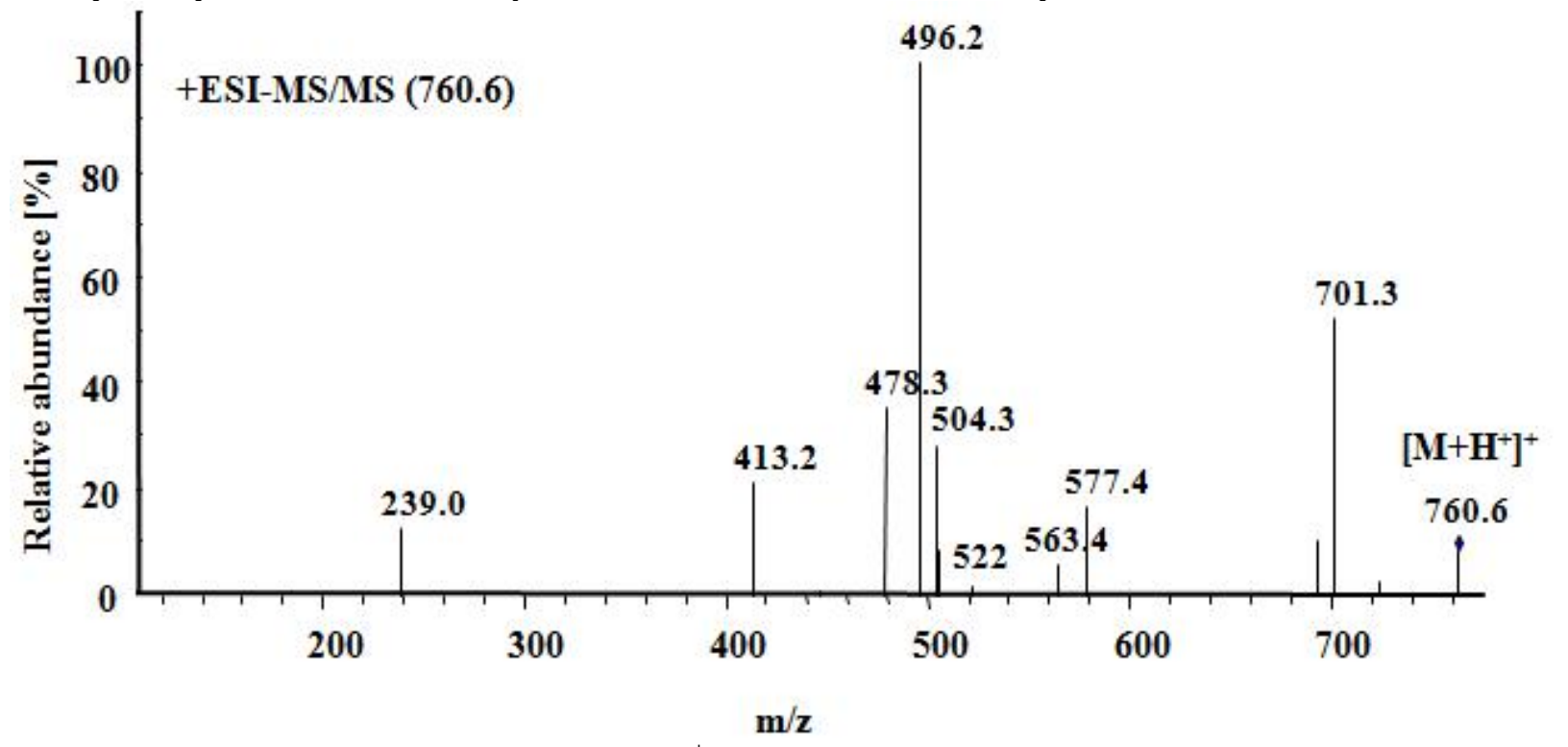

Fig. 2. +ESI MS/MS of POPC of $\mathrm{m} / \mathrm{z760.6}[\mathrm{M}+\mathrm{H}]^{+}$. The neutral lossof183Da confirmed the compound as POPC with fatty acids combination of(16:0/18:1).

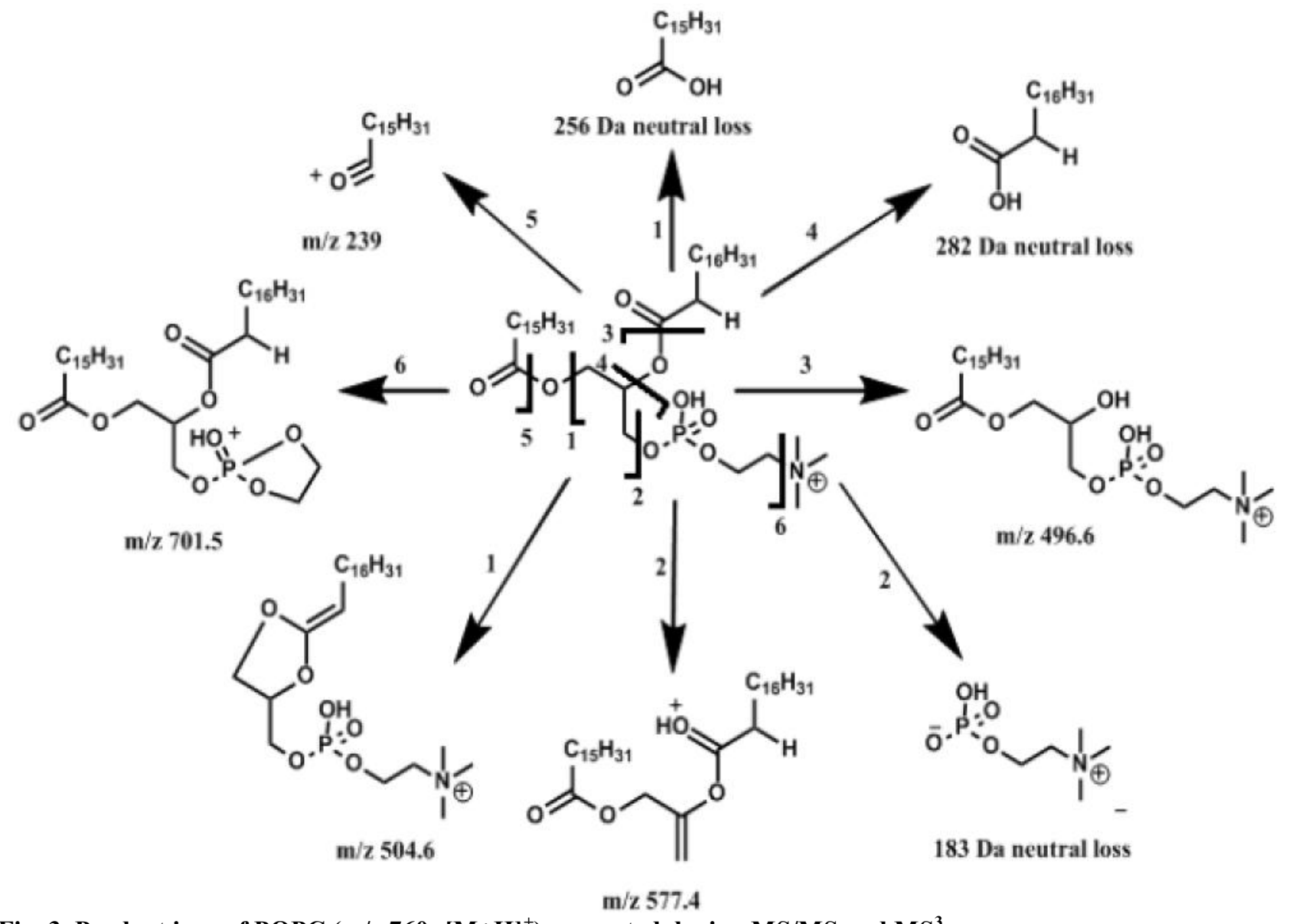

Fig. 3. Product ions of POPC (m/z 760; $\left[\mathrm{M}+\mathrm{H}^{+}\right)$generated during $\mathrm{MS} / \mathrm{MS}$ and $\mathrm{MS}^{3}$. 


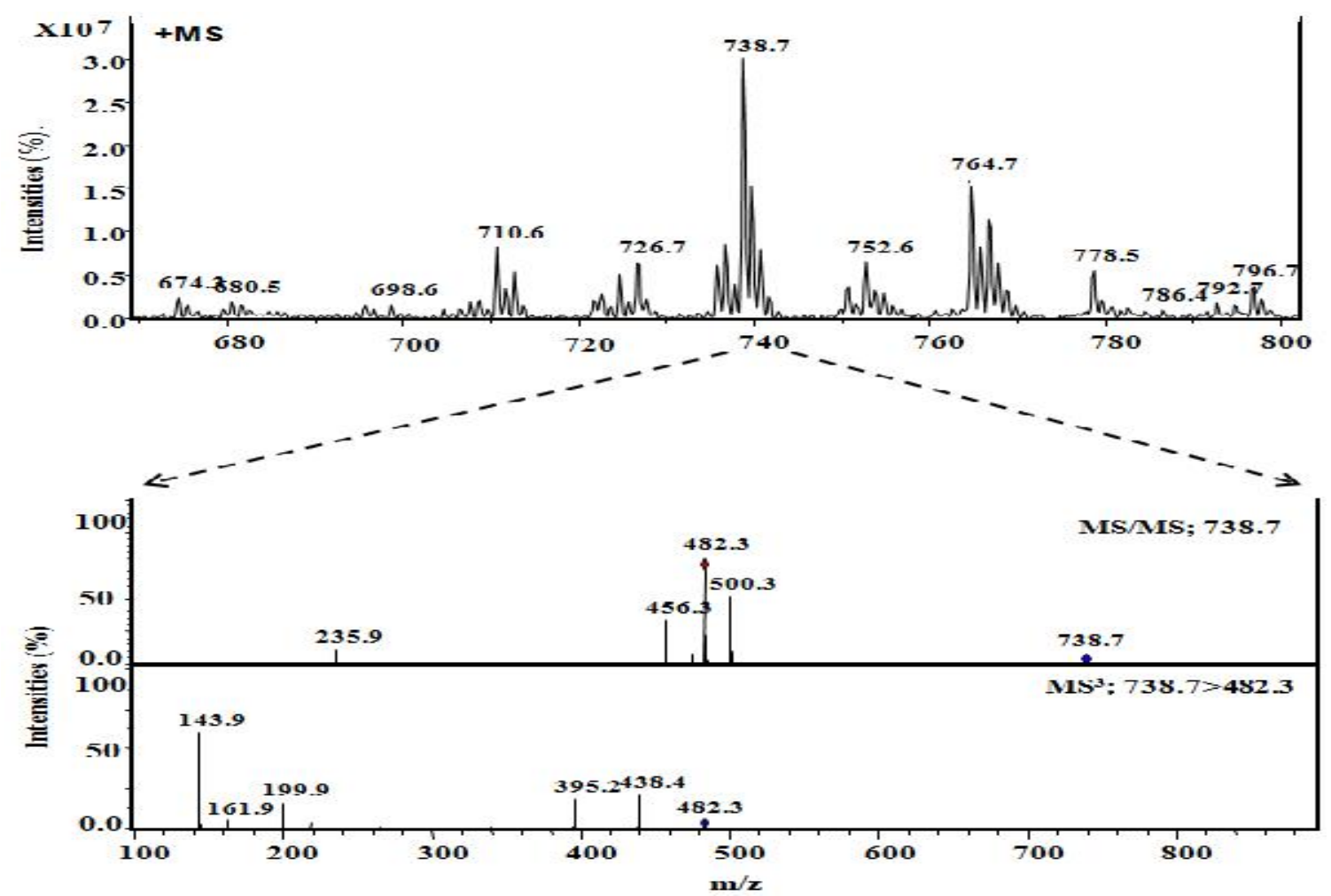

Fig. 4. Diacylglcerol-N,N,N-trimethylhomoserine in soil sample. The ion at $\mathrm{m} / \mathrm{z} 738.7$ was the intense ion that yielded diagnostic product ion for the head group at $\mathrm{m} / \mathrm{z} 144$ during $\mathrm{MS}^{3}$.

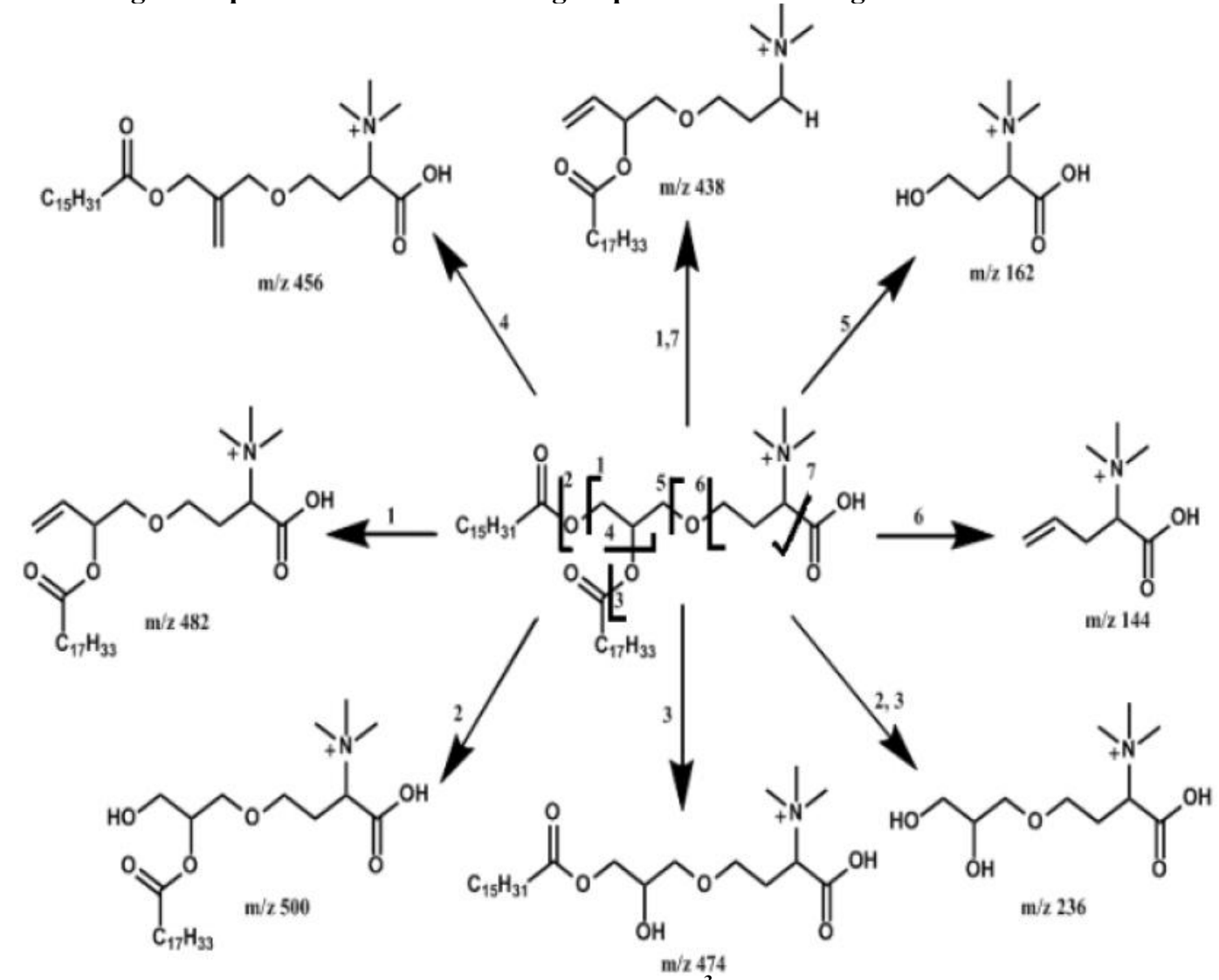

Fig. 5. Product ions of DGTS generated during MS/MS and $\mathrm{MS}^{3}$. 


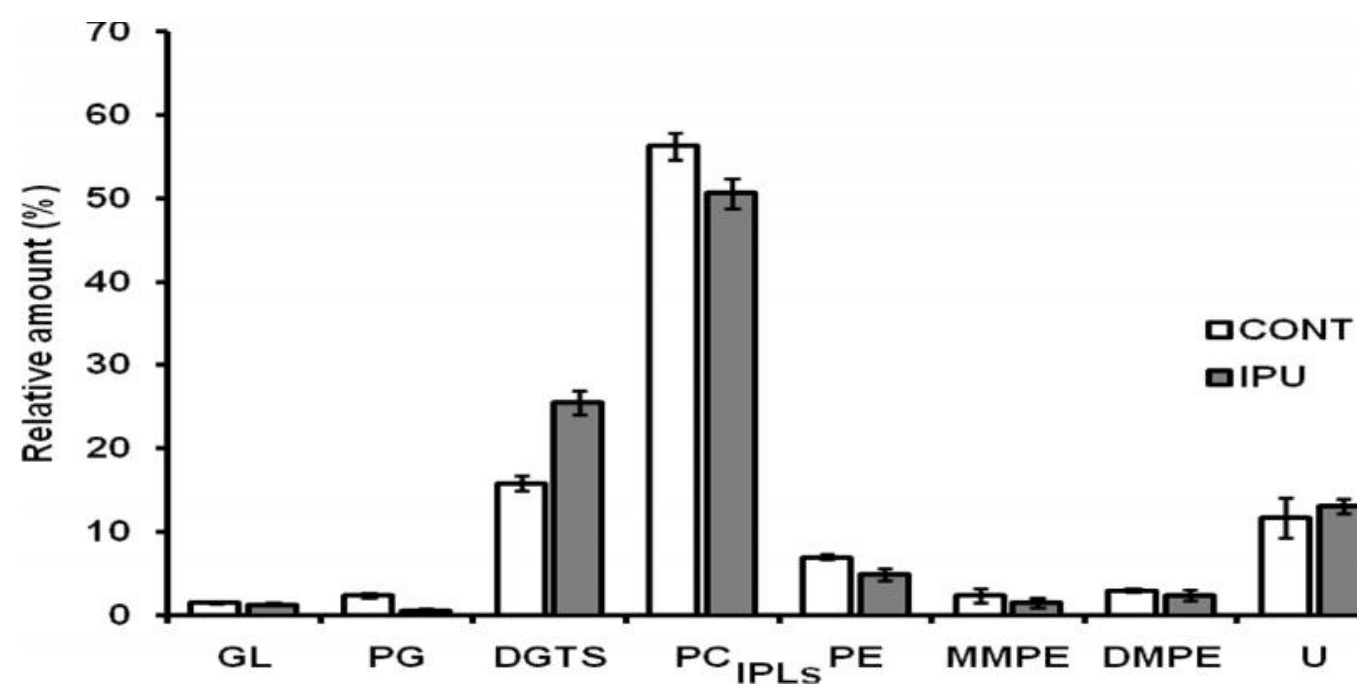

Fig. 6. Relative amounts of controlled and IPU treated soil with standard error (level of significance $p<0.05$ )

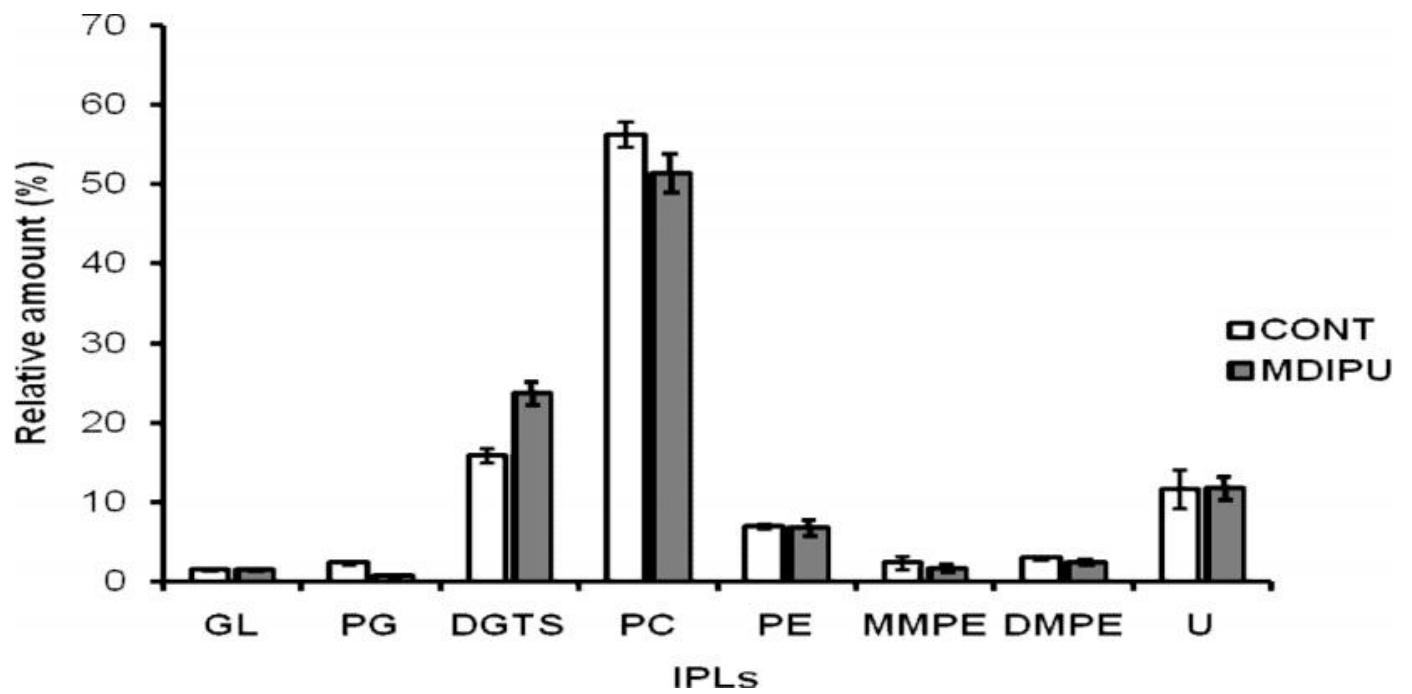

Fig. 7; Relative amounts of controlled and MDIPU treated soil with standard error (level of significance $p<0.05$ )

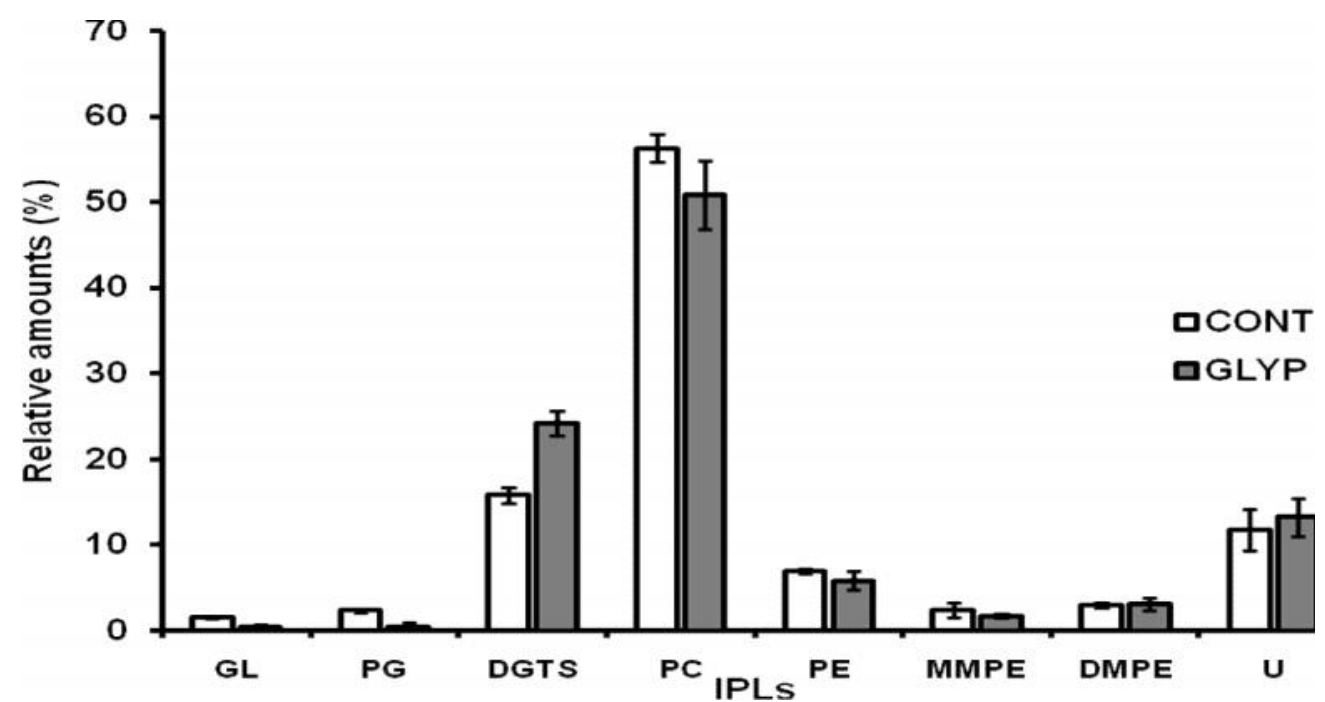

Fig. 8. Relative amounts of controlled and GLYP treated soil with standard error (level of significance $p<0.05$ ) 


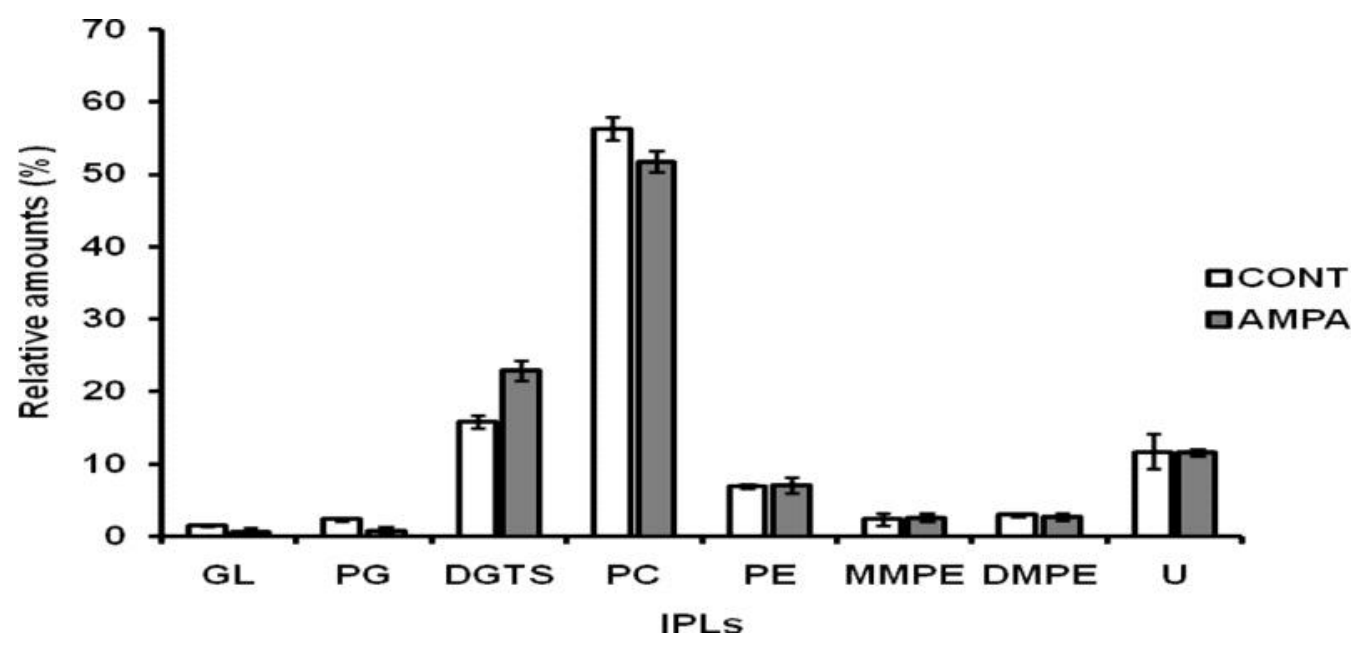

Fig. 9. Relative amounts of controlled and AMPA treated soil with standard error (level of significance p<0.05)

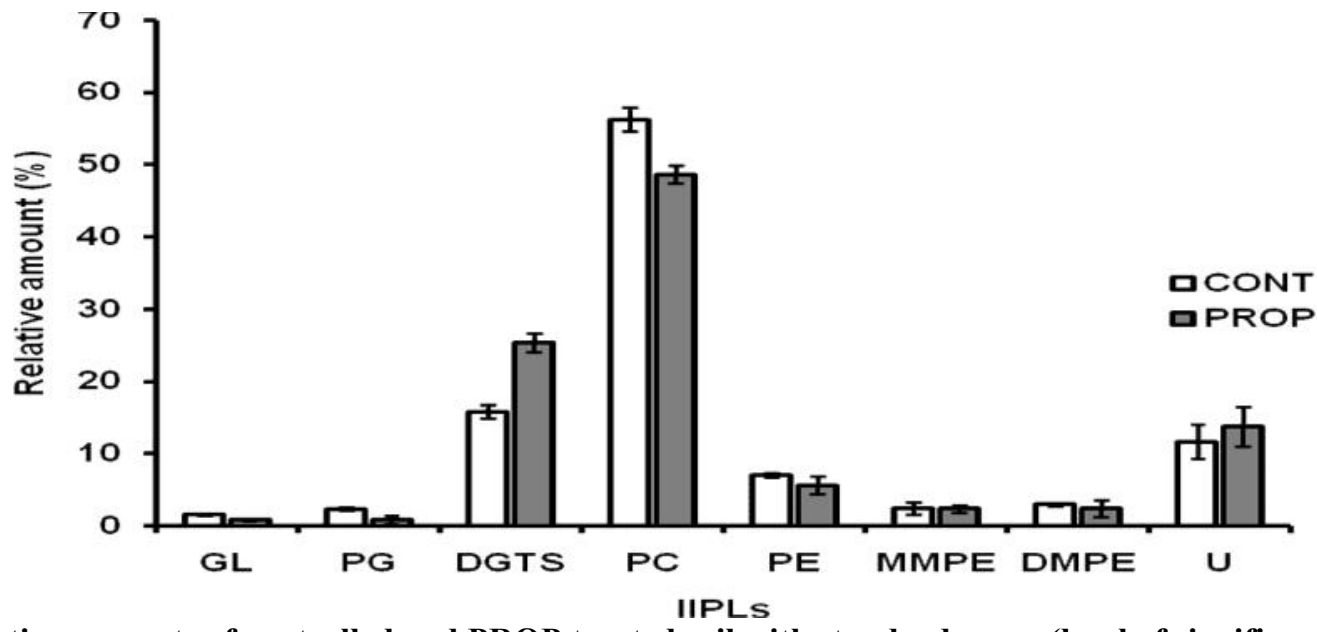

Fig. 10. Relative amounts of controlled and PROP treated soil with standard error (level of significance $p<0.05)$

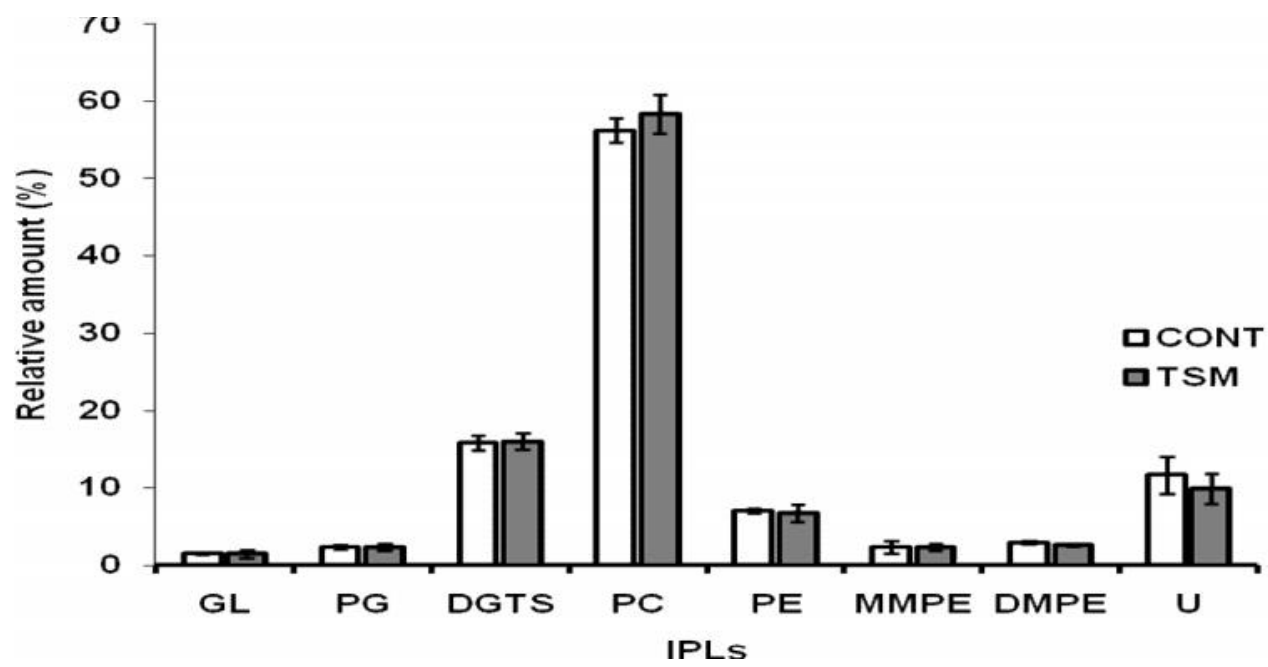

Fig. 11. Relative amounts of controlled and TSM treated soil with standard errors (level of significance $\mathbf{p}<0.05$ ) $\mathrm{GL}=$ glycolipids, $\mathrm{PG}=$ phosphotidyl glycerol, DGTS = diacylglycerol trimethylhomoserine,

$\mathrm{PC}=$ phosphotidyl choline, $\mathrm{PE}=$ phosphotidyl ethanolamine, MMPE $=$ monomethyl phosphotidyl ethanolamine, DMPE $=$ dimethyl phosphotidyl ethanolamine, $\mathrm{U}=$ unknown compound, CONT = control, IPU = isoproturon, MIPU = monodemthyl isoproturon, PROP = propyzamide, GLYP= glyphosate, $\mathrm{AMPA}=$ aminomethyl phosphonic acid, TSM= thifensulfuron methyl, 


\section{DISCUSSION}

An ESI LCMSn method for the analysis of IPLs of the soil microbial communities was used during this study. The chromatographic separation of different classes of polar lipids was achieved using normal phase columns with a gradient solvent combination. Several LC methods have been reported to achieve separation of polar lipids on silica column using methanol, chloroform and an aqueous buffer (Zink and Mangelsdorf, 2004; Becart et al., 1990). These methods were either suffered from poor resolution or used high alkaline $\mathrm{pH}$ that is not suitable for silica column. Keeping these problems in view, the present method was developed to effectively separate polar lipids on silica column using an ammonium salt to prevent the degradation of column (Guan et al., 2001). Generally, separation of phospholipids on silica is achieved by adsorption mechanisms with elution being on the basis of the polar head groups (Andrikopoulos, 2002). Polar lipids separated on silica analysed by ESI LC-MS has allowed the analysis of very low levels of lipids both qualitatively and quantitatively (Zink and Mangelsdorf, 2004; Zink et al., 2008). The analysis of polar lipids was carried out in positive mode ESI and lipid classes were identified on the basis of their retention times, their dissociation patterns and neutral loss of their head groups during MS/MS or $\mathrm{MS}^{3}$.

The relative abundance of $\mathrm{PC}$ in all the samples was found higher than the other polar lipids. PC was found in the range of 49.10 to $55.45 \%$ in the soil samples. Relatively high amount was found in the controlled sample $(55.45 \%)$ while lowest abundance was detected for MDIPU (49.10\%). The relative abundance of PC varies due to pesticides application. PROP- and MDIPU-treated soil samples showed significantly lower amounts of PC than the controlled, however, no significant difference was found among the pesticidesand their TPs-treated soils including PROP and MDIPU. $\mathrm{PC}$ is the main phospholipid present in eukaryotic cells (López-Lara and Geiger, 2001); it is also known to occur within certain bacteria having some symbiotic interaction with eukaryotes (Aktas et al., 2010). PC is the major microbial membrane lipid identified in rhizobia and is associated with normal growth, effective symbiosis and nodule formation within certain plant roots (De Rudder et al., 2000; Sohlenkamp et al., 2003). PC is strongly related to the growth of S. meliloti and any change in PC concentration drastically reduce the growth of to the $\mathrm{S}$. meliloti (Tahara et al., 1994). The high level of PC in the samples indicates a major contribution from organisms other than the bacterial domain, e.g., fungi and algae, however some plant pathogenic bacteria also contain higher levels of PC (López-Lara et al., 2003).

The analysis of IPLs of the controlled and pesticides treated soils revealed that DGTS was the second most abundant lipid in the soil samples. The relative abundance of DGTS was in the range of 15.74 to $25.48 \%$ with the minimum value being for the control and maximum for the IPU were found. Contrary to other polar lipids, these lipids do not have phosphous or carbohydrate groups in their structures. Very limited information is available about their occurrence in environmental samples. The betaine lipids are commonly found in algae, ferns, mosses, lichens and fungi (Evans et al., 1982; Dembitsky 1996; Künzler and Eichenberger 1997). Although, betaine lipids are not generally reported from bacterial strains, recent studies on betaine lipids distributions in the sulfate-reducing bacterium Desulfotomaculum putei indicated their wide distribution in the bacterial domain (Florence et al., 2009). The purple non-sulfur bacterium Rhodobacter spaeroides and Sinorhizobium meliloti, plant nodule forming bacteria replace their membrane phospholipids under phosphate limiting conditions (Benning et al., 1995; Geiger et al., 1999; López-Lara et al., 2005). Although several types of betaine lipids are documented so far, 1, 2-diacylglyceryl$\mathrm{N}, \mathrm{N}, \mathrm{N}$ - trimethyl homoserine (DGTS) is the most frequently reported compound of this group (Basconcillo et al., 2009; López-Lara et al., 2005; Florence et al., 2009). DGTS was present in control and pesticide-treated soil samples. The IPL distributions of the control and treated soils revealed some variations among certain groups of IPLs which were mirrored in the increase of DGTS. With the exception of TSM, the relative level of DGTS was found to be significantly higher than that of control for all pesticides and their TPs.

DGTS is a phosphous free betaine lipid that is mainly produced by organisms such as S. meliloti under phosphate limiting conditions and can partially re place PC (López-Lara et al., 2005). Regardless of stress conditions, some organisms such as algae and some pathogenic fungi produce DGTS in large amounts under normal condition (Evans et al., 1982; Evans and Kates 1984; Vanitha et al., 2007). Thus, the difference might be a general response to the pesticides by certain microbes or it might be sign of an enhanced growth of algae responsible for the enhanced DGTS production.

GLYP is worldwide used as a broad spectrum herbicide. GLYP is degraded by soil microorganisms and converted to its main TP, AMPA, and finally undergoes further mineralisation to release the phosphate moiety which can readily be available for uptake by microorganisms. Accordingly, the increase in DGTS might be due to the suppression of a specific group of microorganism that predominantly produce phosphate based polar lipids. During phosphate limiting conditions, DGTS replaces phosphate based polar lipids. Nevertheless, the high abundance of DGTS even in the presence of phosphates suggests a more general response of microbes towards the stressed conditions. AMPA treatment gave rise to a very similar effect. 
Treatment of IPU, MDIPU and PROP led to significantly higher GDTS relative abundances. Although MDIPU, IPU and PROP are structurally different to GLYP and AMPA, their impact on the IPLs of the soil microbial community was similar. Although TSM was applied at a rate two fold greater than its maximum recommended rate, the resultant soil IPL pattern was similar to that of the control. TSM is a highly selective, low persistence herbicide that is applied at very low volume, and as such, is considered as a safe herbicide.

Glycerophospho ethanolamine (PE) is one of the major polar lipids, being widespread in gram negative and gram positive bacteria (Zink et al., 2008). PE with its monomethyl (PMME) and dimethyl (PDME) congeners were detected in the soil samples. The relatively high abundances of PMME and PDME indicate the contribution of bacterial biomass (Wilkinson, 1988). The presence of PMME and PDME at relatively high levels also suggests that some microorganisms may synthesize $\mathrm{PC}$ via methylation of $\mathrm{PE}$. Nonetheless, other pathways of PC synthesis, including condensation of choline with CDP-diacylglyceride, cannot be neglected, particularly as some organisms, such as S. meliloti, can utilise both pathways for PC synthesis (Sohlenkamp et al., 2000). PE is an essential component of the lipid membrane bilayer and plays an important functional role. PE is the most abundant class of phospholipid in E.coli and its depletion can significantly affect the secretion of certain enzymes e.g., alkaline phosphatase (Mikhaleva et al., 2001). PE, PMME and PDME are widely distributed in microorganisms. They are found in nitrifying bacteria, sulfate reducing bacteria (Barridge and Shively 1968), Fe oxidizers (Short et al., 1969), fermentative bacteria, methanotrophs (Fang et al., 2000), thermophilic bacteria (Card et al., 1969), and eukaryotic algae. PE along with PC is a major IPL of nitrifying and photosynthetic bacteria, and PE along with PG dominate the phospho lipids in heterotrophic bacteria (Lascelles and Szilagyi 1965; Goldfine and Hagen 1968).

The enhanced level of PDME may resulted either from subsequent methylation of PE and PMME and/or from fast methylation of PMME to PDME. The accumulation of PDME can also suggest the synthesis of PC via a pathway other than PE methylation. PE, PMME and PDME were less abundant in the soil treated with IPU than in the control. The lowest values of PE $(9.1 \%)$, PMME (2.5\%) and PDME (4.6\%) may result from general reduction in PE synthesis due to IPU application. Although, MDIPU-treated soil had $2.7 \%$ of PMME, its higher PE (15.5\%) and PDME suggest a different microbial response compared with its parent compound IPU. The PROP and TSM-treated soils also had nearly the same impact on the soil microbes except some subtle variations in their PMME abundance levels. The overall distributions of PE, PMME and PDME for all samples reveal that the relative abundances of both $\mathrm{PE}$ and
PMME varied but there were no pronounced changes in the relative abundance of PDME.

GL: Glycolipids are widespread membrane lipids in plants, animals and bacteria (López-Lara et al., 2003). Under phosphate limiting conditions certain organisms produce glycolipids containing glucose and galactose in their head groups (Benning et al., 1995). The soil samples also contained some glycolipids with mono hexose in their head groups. The relative abundances of GL were in line with those of the control except some minor variations in the abundance of the individual molecular species. Significantly lower levels of GL were detected in the AMPA- treated soil, whereas GLYP-treated soil contained higher relative abundance than AMPA-treated soil but lower than the control.

PG: PG is widely distributed from plant (Holmback et al., 2001) to animals and microbes (Nahaie et al., 1984; Yagüe et al., 1997; Mangelsdorf et al., 2005). The relative abundance of PG of the control is slightly higher than the pesticide-treated soils. The relatively lower abundance of PG in pesticide-treated soil samples could be a general response of certain microbial community producing $\mathrm{PG}$ as a major membrane lipid, toward the pesticide application.

The impacts of pesticides and their TPs were clearly observed in the soils treated with AMPA, GLYP, MDIPU, IPU and PROP. As these herbicides are applied at high rates and have been reported as persistent, they might be expected to influence changes in the membrane lipids of soil microbes. The extent of the change and their impact on the normal functioning of the microbe is still unclear. It is important, however, to develop sustainable agricultural practices and get high productivity for a long period of time with minimal disturbance of the environment. GLYP has been reported in the past to alter the microbial community structure and to increase the soil respiration rate, a reflection of the microbial activity, by enhancing the growth of actinomycetes. Bacterial growth was negatively affected by GLYP application (Araùjo et al., 2003) Missing in references section. Notably, however, at normal application rate glyphosate has been reported to have no impact on soil microbial community structure (Ratcliff et al., 2006). TSM has been reported to reduce the growth of a few strains of fluorescent pseudomonas at very high application rate. IPU has been reported to have inhibiting effects on soil bacterial activity even at the permissible concentration (Widenfalk et al., 2004). Neither PROP nor its TPs have been investigated extensively for its impact on soil microbial community.

Conclusion: Membrane lipids including phospholipids and their fatty acids side chains often give evidence of adaptations by showing for instance, response to changing nutrient availability, temperature or pressure. 
The adaptation process might be associated with the changes in fatty acids carbon numbers and their saturation or unsaturation. The previous studies related to the impact of pesticides on polar membrane lipids have mainly involved utilization of PLFA, hence information about the head groups are lost during analysis. Fatty acyl chains of some specific groups of polar lipids are susceptible to change and others remain unchanged. Significant variations among the molecular species of some individual classes were measured. The greatest changes were observed among the PE, PMME, PG and MGDG molecular species, while minimal variations were found for the PC and DGTS classes of lipids. It is important to observe changes in the abundances of different classes of IPLs, and to monitor the variations within an individual class with respect to their fatty acids inventories for the assessment of the impact of any xenobiotic or environmental stress.

It also reveals that the pesticides might not affect the fatty acid subunits of all the groups of lipids equally but might bring significant changes in the fatty acids pattern of some specific groups of lipids. Further laboratory based research is needed to identify some intact polar lipids bio-markers for certain important soil microbes actively involved in different nutrient cycles e.g., nitrogen cycle and to observe their response to certain stress conditions including agricultural practices etc. The combination of IPL analysis with other techniques including FAME and PLFA analysis and DGGE to assess the functional changes related to pesticides application can be very useful to understand the soil microbial ecology.

Acknowledgements: We would like to thank The Higher education Commission of Pakistan for the financial support. The York Centre of Excellence in Mass Spectrometry was created thanks to a major capital investment through Science City York, supported by Yorkshire Forward with funds from the Northern Way Initiative.

\section{REFERENCES}

Aktas, M., M. Wessel, S. Hacker, S. Klüsener, J. Gleichenhagen and F. Narberhaus (2010). Phosphatidyl choline biosynthesis and its significance in bacteria interacting with eukaryoteic cells. European. J. Cell Biol. 89(12):888-894.

Andrikopoulos, N. K (2002). Chromatographic and spectroscopic methods in the analysis of triacylglycerol species and regiospecific isomers of oils and fats. Critical Reviews in Food Sci. Nutri. 42(5): 473-505.

Araújo, A. S. F., R.T.R. Monteiro, and R.B. Abarkeli (2003). Effect of glyphosate on the microbial activity of two Brazilian soils. Chemosphere, 52(5): 799-804

Arias, M. E., J. A. González-Pérez, F. J. González-Vila and A.S. Ball (2005). Soil health: a new challenge for microbiologists and chemists. Int. Microbiol. 8(1):13-21.

Baldrian P, T. Vetrovsky, T. Cajthaml, P. Dobiasova, M. Petrankova, J. Snajdr and I. Eichlerova (2013). Estimation of fungal biomass in forest litter and soil. Fungal Ecol. 6: 1-11

Barridge, J. K. and J.M. Shively (1968). Phospholipids of the thiobacilli. J. Bacteriol. 95(6):2182-2185.

Basconcillo, L. S., Zaheer, R., Finan, T. M., and B.E. McCarry (2009). A shotgun lipidomics approach in sinorhizobium meliloti as a tool in functional genomics. J. Lipid Res. 50(6):1120-1132.

Becart, J., C. Chevalier, and J. Biesse (1990). Quantitative analysis of phospholipids by HPLC with a light scattering evaporating detector application to raw materials for cosmetic use. J. High Resolution Chromatr., 13(2):126-129.

Bending, G. D., M. S. Rodríguez-Cruz, and S. D. Lincoln (2007). Fungicide impacts on microbial communities in soils with contrasting management histories. Chemosphere. 69(1):82 88.

Benning, C., Z. H. Huang and D. A. Gage (1995). Accumulation of a novel glycolipid and a betaine lipid in cells of rhodobacter sphaeroides grown under phosphate limitation. Archives of Biochem.Biophy. 317(1):103 - 111.

Bligh, E. G. and W.J. Dyer (1959). A rapid method of total lipid extraction and purification. Can. J. Biochem. Physiol. 37(8):911-917.

Card, G. L., Georgi, C. E., and W.E. Militzer (1969). Phospholipids from bacillus stearothermophilus. J. Bacteriol. 97(1):186-192.

De Rudder, K. E. E., I. M. López-Lara, and O. Geiger (2000). Inactivation of the gene for phospholipid n-methyltransferase in sinorhizobium meliloti: phosphatidyl choline is required for normal growth. Mol. Microbiol. 37(4):763-772

Dembitsky, V. M. (1996). Betaine ether-linked glycerolipids: Chemistry and biology. Progress in Lipid Res. 35(1): $1-51$.

Evans, R., M. Kates, and G. Wood (1982). Identification of diacylglycerolo-(N,N,N-trimethyl)homoserine in the halotolerant alga, dunaliella parva. Chem. Phy. of Lipids, 31(4):331-338.

Evans, R. W. and M. Kates (1984). Lipid composition of halophilic species of dunaliella from the dead sea. Archives of Microbiol.140:50-56.

Fang, J., Michael, J. B., and D.S. Jeremy (2000). Characterization of methanotrophic bacteria on the basis of intact phospholipid profiles. FEMS Microbiol. Letters, 189(1):67 - 72. 
Florence, S., S. G. Wakeham, J. S. Lipp, H. F. Fredricks, and K. U. Hinrichs (2009). Detection of microbial biomass by intact polar membrane lipid analysis in the water column and surface sediments of the black sea. Environ. Microbiol. 11(10):2720 - 2734 .

Geiger, O., R. Viola, W. Barbara, T. M. Finan, and J. T. Oates (1999). The regulator gene phob mediates phosphate stress-controlled synthesis of the membrane lipid diacylglyceryl-N,N,N-trimethyl homoserine in rhizobium (sinorhizobium) meliloti. Mol. Microbiol. 32(1):63-73.

Goldfine, H., and P. O. Hagen (1968). N-Methyl Groups in Bacterial Lipids III. Phospholipids of Hyphomicrobia. Microbial Physiology and Metabolism: J. Bactriol. 95(2):367

Graham, J., N. Hodge, and J. Morton (1995). Fatty acid methylester profiles for characterization of glomalean fungi and their endomycorrhizae. Appl. Environ. Microbiol., 61(1):58-64.

Guan, Z., J. Grünler, S. Piao, and P. J. Sindelar (2001). Separation and quantitation of phospholipids and their ether analogues by high performance liquid chromatography. Anal. Biochem. 297(2):137- 143.

Hsu, F. F. and T. John (2009). Electrospray ionization with low-energy collisionally activated dissociation tandem mass spectrometry of glycerol phospholipids: Mechanisms of fragmentation and structural characterization. J. Chromatr. B. 877(26):2673 - 2695.

IBM Corp. Released 2010. IBM SPSS Statistics for Windows, Version 19.0. Armonk, NY: IBM Corp

Künzler, K. and W. Eichenberger (1997). Betaine lipids and zwitter ionic phospholipids in plants and fungi. Phytochem. 46(5):883 - 892.

Lascelles, J. and Szilagyi, J. F. (1965). Phospholipid synthesis by rhodopseu domonas spheroidesin relation to the formation of photosynthetic pigments. J. Gen. Microbiol., 38(1):55-64.

Laura, V., J. Del Campo, R. Guerrero, and R. Geyer(2010). Intact phospholipid and quinone biomarkers to assess microbial diversity and redox state in microbial mats. Microb. Ecol. 60(1):226-238.

López-Lara, I. M., J. L. Gao, M. J. Soto, A. SolaresPérez, B. Weissenmayer, C. Sohlenkamp, G. P. Verroios, J. Thomas-Oates, and O. Geiger (2005). Phosphous-free membrane lipids of sinorhizobium meliloti are not required for the symbiosis with alfalfa but contribute to increased cell yields under phosphous-limiting conditions of growth. Mol. Plant-Microbe Int. 18(9):973-982.
López-Lara, I. M., C. Sohlenkamp, and O. Geiger (2003). Membrane lipids in plant-associated bacteria: Their biosyntheses and possible functions. Mol. Plant-Microbe Int. 16(7):567-579.

López-Lara, M. I. and O. Geiger (2001). Novel pathway for phosphatidyl choline biosynthesis in bacteria associated with eukaryotes. J. Biotech. 91(23): $211-221$.

Mangelsdorf, K., Zink, K.-G., Birrien, J.-L., and L. Toffin (2005). A quantitative assessment of pressure dependent adaptive changes in the membrane lipids of a piezosensitive deep sub-seafloor bacterium. Organic Geochem. 36(11):1459 1479.

Martins, J. D., J. Monteiro, M. Antunes-Madeira, A. Jurado, and V. Madeira (2003). Use of the microorganism bacillus stearothermophilus as a model to evaluate toxicity of the lipophilic environmental pollutant endosulfan toxicology in Vitro, 17(5-6):595-601. Twelfth International Workshop on In vitro Toxicology.

Mikhaleva, N. I., V. V. Golovastov, S. N. Zolov, M. V. Bogdanov, W. Dowhan, and M. A. Nesmeyanova (2001). Depletion of phosphatidyl ethanolamine affects secretion of escherichia coli alkaline phosphatase and its transcriptional expression. FEBS Letters, 493(2-3):85 - 90.

Nahaie, M. R., Goodfellow, M., Minnikin, D. E., and V. Hajek (1984). Polar lipid and isoprenoid quinone composition in the classification of staphylococcus. J Gen Microbiol, 130(9):24272437.

Pankhurst, C..E, B. G. Hawke, H. J. McDonald, J. C. Buckerfield, P. O. Michellsen,K. A. O’Brien, V. V. Gupta, and S R, B. M. Doube (1995). Evaluation of soil biological properties as potential bio-indicators of soil health. Aus. J. Exp. Agric. 35:1015-1028.

Peacock, A. D., M. D. Mullen, D. B. Ringelberg, D. D. Tyler, D. B. Hedrick, P. M. Gale, and D. C. White (2001). Soil microbial community responses to dairy manure or ammonium nitrate applications. Soil Biol. Biochem. 33(7-8):1011 1019.

Pulfer, M. and R. C. Murphy (2003). Electrospray mass spectrometry of phospholipids. Mass Spectrom. Rev. 22(5):332-364.

Ratcliff,A.W.,Busse,M.D.,andShestak,C.J.(2006). Changes in microbial community structure following herbicide (glyphosate) additions to forest soils. Applied Soil Ecology, 34(2-3):114 124.

Seghers, D., K. Verthé, D. Reheul, R. Bulcke, S. D. Siciliano, W. Verstraete, and E.M. Top (2003). Effect of long term herbicide applications on the 
bacterial community structure and function in an agricultural soil. FEMS Microbiol. Ecol. 46(2): $139-146$.

Short, S. A., D. C. White, and M. I. H. Aleem (1969). Phospholipid Metabolism in Ferrobacillus ferrooxidans. J. Bacteriol. 99(1):142-150.

Sohlenkamp, C., K. E. E. De Rudder, V. Röhrs, I. M. López-Lara, and O. Geiger (2000). Cloning and characterization of the gene for phosphatidyl choline synthase. J. Biol. Chem. 275(25):1891918925.

Sohlenkamp, C., I. M. López-Lara, and O. Geiger (2003). Biosynthesis of phosphatidyl choline in bacteria. Progr. Lipid Res. 42(2):115-162.

Sturt, H. F., R. E. Summons, K. Smith, M. Elvert, and K.U. Hinrichs (2004). Intact polar membrane lipids in prokaryotes and sediments deciphered by high performance liquid chromatography/electrospray ionization multistage mass spectrometry as new biomarkers for biogeochemistry and microbial ecology. Rapid Commun. Mass Spectrom, 18(6):617 - 628 .

Suleman, M. and B. J. Keely (2019). Laboratory simulation studies of the leaching of priority pesticides and their transformation products in soils. The JAPS. 29(4):1112-1126.

Tahara, Y., T. Yamashita, A. Sogabe, and Y. Ogawa (1994). Isolation and characterization of Zymomonas mobilis mutant defective in phosphatidyl ethanolamine-N-methyltransferase. J. Gen. Appl. Microbiol. 40: 389-396.

Torsvik, V., F. L. Daae, R. A. Sandaa, and L. Ovreas (1998). Novel techniques for analysing microbial diversity in natural and perturbed environments. J. Biotech. 64(1):53 - 62 .

Van Elsas, J. D., G. F. Duarte, A. Keijzer-Wolters, and E. Smit (2000). Analysis of the dynamics of fungal communities in soil via fungal-specific PCR of soil DNA followed by denaturing gradient gel electrophoresis. J. Microbiol. Methods 43(2):133 - 151 .

Vanitha, A., M. S. Narayan, K. N. C. Murthy, and G. A. Ravishankar (2007). Comparative study of lipid composition of two halotolerant alga dunaliella bardawil and dunaliella salina. International J.Food Sci. Nut. 58(5):373-382.

Widenfalk, A., Svensson, J. M., and W. Goedkoop (2004). Effects of the pesticides captan, deltamethrin, isoproturon, and pirimicarb on the microbial community of a freshwater sediment. Environ. Toxicol. Chem. 23(8):1920-1927.

Willers, C., P. Jansen van Rensburg, and S. Claassens (2015), Microbial signature lipid biomarker analysis- an approach that is still preferred, even amid various method modifications. J. Appl. Microbiol. 118: 1251-1263.

Wilkinson, S.G. (1988). Gram-negative bacteria. In Microbial Lipids, 1, Eds. C. Ratledge and S.G. Wilkinson, Academic Press, London. pp. 299. 488.

Zelles, L. (1999). Fatty acid patterns of phospho lipids and lipo polysaccharides in the characterisation of microbial communities in soil: a review. Biology and Fertility of Soils, 29(2):111-129.

Zink, K. -G., H. Wilkes, U. Disko, M. Elvert, and B. Horsfield (2003). Intact phospholipids-microbial "lifemarkers" in marine deep subsurface sediments. Organic Geochem. 34(6):755 - 769

Zink, K.-G. and K. Mangelsdorf (2004). Efficient and rapid method for extraction of intact phospholipids from sediments combined with molecular structure elucidation using LC- ESIMS/MS analysis. Anal. Bioanal. Chem. 380(5):798-812.

Zink, K.-G., K. Mangelsdorf, L. Granina, and B. Horsfield (2008). Estimation of bacterial biomass in subsurface sediments by quantifying intact membrane phospholipids. Anal. Bioanal. Chem. 390(3):885-896. 